\title{
Differentiation of wood species using headspace fingerprinting through Fourier-transform infrared spectroscopy
}

\author{
Justine M. Kalaw ${ }^{1}$ E Fortunato Sevilla III ${ }^{* 1,2}$ \\ ${ }^{1}$ Graduate School; ${ }^{2}$ Research Center for the Natural and Applied Sciences, \\ University of Santo Tomas, España Boulevard, 1015 Manila, The Philippines
}

\begin{abstract}
An innovative technique in the differentiation of five wood species (Pterocarpus indicus, Acacia auriculaeformis, Gmelina arborea, Vitex parviflora, and Diospyros philippinensis) was carried out using headspace Fourier-transform infrared spectroscopy (FTIR) and chemometrics. The unique headspace fingerprint of each wood species was obtained through an extractive headspace FTIR analysis. The FTIR spectra included absorption peaks which indicated the presence of several functional groups, but the use of the spectra alone for discrimination is visually difficult and too complex. Through the use of principal component analysis (PCA) and hierarchical cluster analysis (HCA), the wood samples were discriminated by their taxonomical species. This study demonstrates the capability of headspace FTIR technique in wood headspace analysis and its potential as a simple, non-destructive, and rapid alternative for wood species identification.
\end{abstract}

Keywords: wood species differentiation, headspace FTIR spectroscopy, chemometric discrimination

\section{INTRODUCTION}

Wood identification is critical in controlling illegal timber trading $[1,2]$. The most commonly used methods are based on the macroscopic and microscopic analysis of wood anatomy. However, these methods are able to identify wood only to the genus level [3]. Physicochemical and genetic methods have been employed to provide information to establish wood identity down to the species level [2]. Most of these methods involve

*To whom correspondence should be addressed: fortunato.sevilla@ust.edu.ph measurements carried out on the solid wood sample.

The headspace above the solid wood sample could also provide information for species identification. It contains the vapor generated by the volatile compounds present in the wood and is responsible for the distinct odor of wood species such as sandalwood (Santalum album L.), 'cigar-box' cedars (Cedrella spp.), and raspberry jam wood (Acacia acuminata Benth.), and conifers (Chamaecyparis spp.) [4-6]. The traditional method for the detection and quantification of odor in the sample headspace is olfactometry, which is based on the judgement 
of human assessors [7]. However, since most wood species have very low concentration of volatile compounds for proper olfactory detection, headspace analysis of wood is commonly carried out using gas chromatography-mass spectrometry (GC-MS) and gas chromatography-mass spectrometry/ olfactometry [5, 8-10]. Analysis of wood headspace has also been carried by means of the electronic nose, which is composed of an array of chemo-electronic sensors that generates electric signals in the presence of vapors [11$15]$.

An innovative technique for wood headspace analysis is headspace Fourier-transform infrared spectroscopy (FTIR). It proves to be highly efficient in analyzing volatile compounds, involving less complexity and lower cost compared to GC-MS. It takes advantage of the unique IR absorption of most volatile chemical species to produce a distinct spectrum of the "headspace fingerprint" of a material [16]. Similar with the complex nature of the chemical fingerprint of solid materials, the headspace fingerprint of solid or liquid materials holds information about the aforementioned material that can be analyzed using chemometrics.

FTIR spectroscopy has been coupled with chemometrics to analyze and differentiate the chemical fingerprints of solid wood samples and extractives from wood samples, including beech [17], rosewood [18], walnut wood species [19], precious wood species [20], dipterocarp wood species [21], and archeological wood samples [22]. It was also used in discriminating the headspace spectral fingerprint of food samples, such as Chinese spirits [16], grapes [23] and strawberries [24], and plant samples such as species of the genus Pandanus [25]. All of which reported the high accuracy and great efficiency of the technique.

This study describes a headspace FTIR technique for the discrimination of five
Philippine wood species using chemometric methods for extracting information from spectral data. It presents a simple, low-cost, accurate and efficient approach for the headspace analysis of wood. It can be applied for the rapid and reliable recognition of wood species in the effort to protect endangered wood species and to control the international trading of illegally cut woods.

\section{Materials AND Methods}

Wood samples. The wood samples used in this study were Ptercarpus indicus (Philippine common name: narra), Vitex parviflora (Philippine common name: molave), Diospyros philippinensis (Philippine common name: kamagong), Acacia auriculaeformis (Philippine common name: acacia), and Gmelina arborea (Philippine common name: gmelina). Pandanus indicus, V. parviflora, and D. philippinensis are premium wood species [26] and are included in the IUCN Red List of Threatened Species [27]. Acacia auriculaeformis and G. arborea are commercial wood species used for sawn timber and pulpwood [28, 29].

Samples were collected from the grounds of the University of Santo Tomas, Manila (14연 $33^{\prime \prime}$ North and $120^{\circ} 59^{\prime} 24^{\prime \prime}$ East), and authenticated by the UST Herbarium, Research Center for the Natural and Applied Sciences, University of Santo Tomas. Stem samples were obtained from healthy and mature trees and were air-dried away from direct sunlight. Four blocks $(3 \mathrm{~cm} \times 3 \mathrm{~cm} \times$ $1.5 \mathrm{~cm}$ ) were chopped from different portions of the stems and were stored in air-tight plastic containers kept in a freezer $\left(<-10^{\circ} \mathrm{C}\right)$ until use. The chopped portions were thawed, debarked and milled before analysis.

Headspace sampling. The headspace of each wood species was sampled through a vaporphase extractive technique. The headspace sampling set-up consisted of a sealed sample container $(50 \mathrm{~mL})$ provided with a stopcock to 
which a $50 \mathrm{~mL}$ gas-tight syringe (Hamilton, Switzerland) was connected. The chopped wood block was heated in this set-up at $80^{\circ} \mathrm{C}$ for $40 \mathrm{~min}$ using a water bath and a hot plate. The generated vapor was collected in the gas syringe.

FTIR spectroscopic analysis. The headspace FTIR spectroscopic analyses of the wood samples were accomplished using a FTIR spectrophotometer (Prestige-21, Shimadzu Corporation, Japan). The extracted headspace sample was placed in a $10-\mathrm{cm}$ gas cell (Pike technologies, USA) with two $24 \mathrm{~mm} \times 4 \mathrm{~mm} \mathrm{KBr}$ windows as the sample holder. Prior to each analysis, the gas cell was purged with nitrogen gas for $10 \mathrm{~min}$. The IR spectrum was measured from 600 to $4000 \mathrm{~cm}^{-1}$ with a resolution of 2.0 $\mathrm{cm}^{-1}$ and 50 scans per analysis.

Data processing and chemometric analysis. The FTIR spectra of the headspace of wood samples were processed using IR solutions software (Shimadzu Corporation). The signals from water vapor (4000-3500 and 2100-1200 $\mathrm{cm}^{-}$ $\left.{ }^{1}\right)$ and $\mathrm{CO}_{2}\left(2300-2250\right.$ and $\left.666 \mathrm{~cm}^{-1}\right)$ were subtracted from the spectra of the samples through an atmospheric correction technique. The spectra were also normalized and underwent baseline correction using the mentioned software.

Principal component analysis (PCA) and hierarchical cluster analysis (HCA) were performed on the spectral data using the XLSTAT software package (Addinsoft, USA). PCA was carried out using an observations/ variable data format and Pearson correlation for data treatment. HCA was done with Pearson correlation coefficient similarity measurement with agglomerative unweighted paired-group average method.

\section{Results AND DISCUSSION}

Headspace generation. The headspace consists of the vapors formed by the volatile compounds in the wood sample during the thermal extraction process. Several factors affected the generation of headspace for FTIR analysis and were optimized for better sensitivity. The factors were quantitatively evaluated using the total of the measured absorbance which is related to the concentration of the gaseous compounds.

The heating temperature affected the headspace build-up of the wood sample, an increase in temperature causing an increase in absorbance. A temperature of $80^{\circ} \mathrm{C}$ was chosen as optimum, since higher temperatures could cause water in the sample to vaporize which could damage the $\mathrm{KBr}$ window of the IR gas cells. The absorbance readings increased as the heating time was prolonged, indicating a higher vapor concentration. The optimum heating time was $40 \mathrm{~min}$, since no significant change was observed in the absorbance when heating was done beyond this period. A temperature of $80^{\circ} \mathrm{C}$ and a 40 min heating period facilitated the release of a great amount of volatile compounds to the sample headspace.

The size of the wood particles (chipped and milled) were found to have no influence on the release of the volatile compounds to the headspace. The absorbance readings of milled and chipped wood samples were not significantly different from each other. Chipped

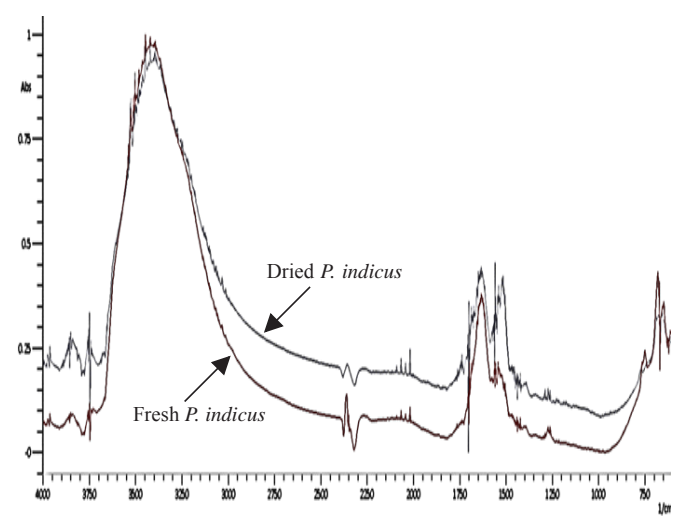

Figure 1. The headspace spectra (4000-600 $\left.\mathrm{cm}^{-1}\right)$ of fresh and dried $P$. indicus 
wood samples were preferred due to practical reasons such as less preparation time and less destruction to the sample.

The headspace spectra of dry and fresh wood samples exhibited some variations in the fingerprint regions, as can be discerned in Fig. 1 which shows the spectra obtained from fresh and dried samples of $P$. indicus. However, the absorption peaks at $3600-3000 \mathrm{~cm}^{-1}$ remained unchanged, indicating that the presence of water vapor in the headspace of the fresh wood samples did not completely interfere with the absorption peaks of other volatile compounds. Thus, the headspace samples were generated from fresh chipped samples which were heated at $80^{\circ} \mathrm{C}$ for $40 \mathrm{~min}$.

IR spectral analysis. The headspace FTIR spectra of the five wood species are presented in Fig. 2. Several differences can be discerned in the spectra of the wood species. Some peaks were present in one or two species while absent in others; some peaks have higher absorbance in comparison to the same peak of the spectrum from a different wood species. In the region of $3550-2900 \mathrm{~cm}^{-1}$, almost similar peaks were visible for all the wood samples which can be attributed to combination of C-H stretching from saturated and unsaturated including cyclic and aromatic compounds, and stretching of $\mathrm{O}-\mathrm{H}$ from alcoholic, phenolic and acidic compounds [30]. In the region of $1700-600 \mathrm{~cm}^{-1}$, the differences between each wood species were clear (Fig. 3), indicating the presence of different compounds in the headspace. The absorption peak at 1529$1502 \mathrm{~cm}^{-1}$ was only evident in headspace of the wood species $V$. parviflora and $D$. philippinensis, while absorption peak at 1277 $1260 \mathrm{~cm}^{-1}$ was mostly visible to $D$. philippinensis only, though A. auriculaeformis also had weak signals in the same wavenumber range. Strong signals at 763 and $749 \mathrm{~cm}^{-1}$ were clear in wood species D. philippinensis and $A$. auriculaeformis. A small peak at $646 \mathrm{~cm}^{-1}$ is exclusive to the wood $P$. indicus, while the

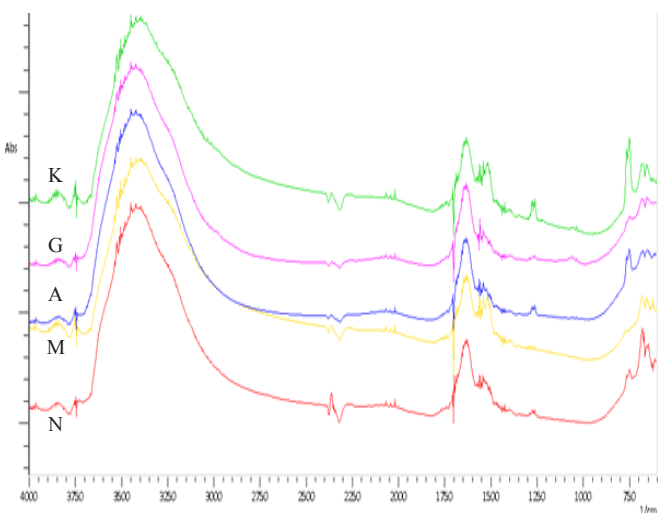

Figure 2. The headspace spectra (4000-600 $\left.\mathrm{cm}^{-1}\right)$ of the five wood species: D. philippinensis $(\mathrm{K}), \mathrm{G}$. arborea (G), A. auriculaeformis (A), V. parviflora $(\mathrm{M})$, and $P$. indicus $(\mathrm{N})$

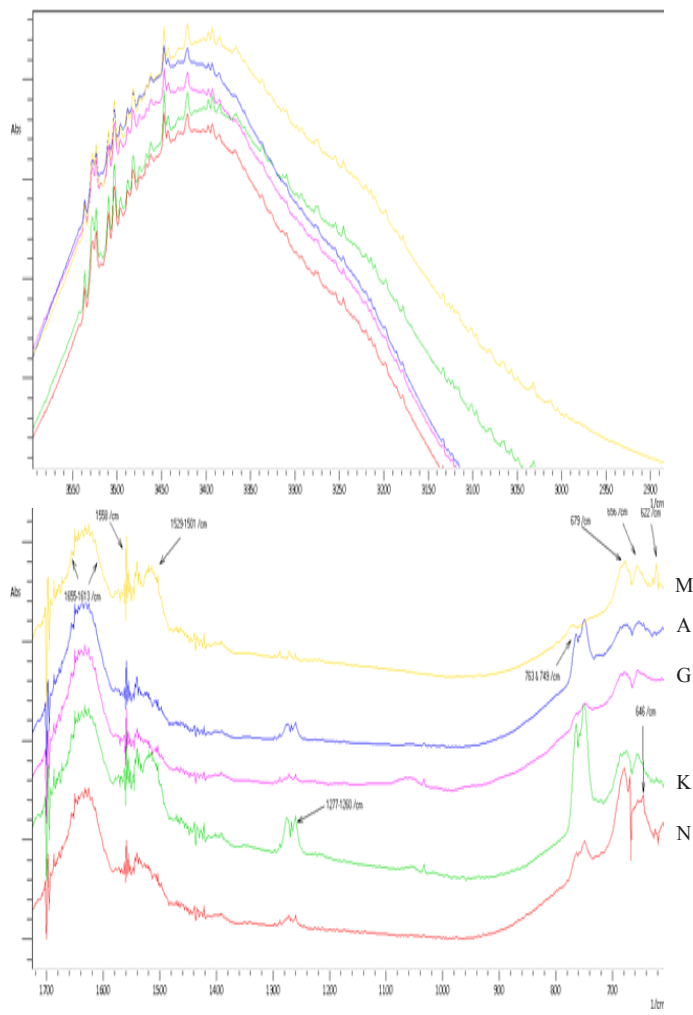

Figure 3. Headspace spectra of the five wood species in wavenumber ranges of $3550-2900 \mathrm{~cm}^{-1}$ (top) and $1700-600 \mathrm{~cm}^{-1}$ (bottom) showing distinct signals: D. philippinensis (K), G. arborea (G), A. auriculaeformis (A), V. parviflora (M), and $P$. indicus $(\mathrm{N})$ 
absorption peak at $622 \mathrm{~cm}^{-1}$ was limited to $V$. parviflora. In spite of the presence and absence of specific absorption peaks of the headspace spectra of wood species, unambiguous distinction between them was still unattainable; therefore, the use of statistical measurements were done to fully discriminate the wood species from their headspace composition.

\section{Chemometric analysis of headspace spectra.}

A chemometric approach was used to explicitly discriminate the headspace of wood samples from each other. Unsupervised pattern recognition techniques were used to discover groupings and distinct patterns between the headspace spectral data of each wood samples. For the IR spectra data analysis, PCA was used because of the large number of data per sample (more than 3000 per sample). However, this large amount of data might be unnecessary for the production of a PCA plot in the aim of discriminating wood species. Therefore, a statistical plot was used to determine which wavenumbers were actually important contributors to the variation for each wood.

The factor loadings plot of the $1^{\text {st }}$ and $2^{\text {nd }}$ principal components (F1 and F2) (Fig. 4) shows the

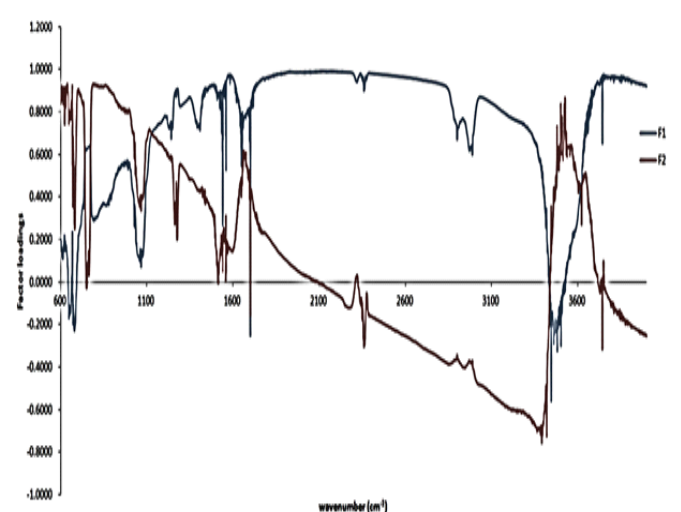

Figure 4. Factor loadings vs. wavenumber (4000-600 $\left.\mathrm{cm}^{-1}\right)$ plot of the $1^{\text {st }}$ and $2^{\text {nd }}$ principal components (F1 and F2) from PCA calculations wavenumber ranges in the FTIR spectral data that has high contribution to the variation of the samples. The wavenumber ranges 600-1750 $\mathrm{cm}^{-1}$ and $3200-3550 \mathrm{~cm}^{-1}$ contain the most variance for the spectral data, while the other wavenumbers have low or none at all. This plot correlates with the headspace spectral analysis in the preceding section wherein it was highlighted that the carbonyl and fingerprint regions, as well as the $3550-2900 \mathrm{~cm}^{-1}$ wavenumber range, have the distinct absorption peaks. With this information, the amount of data for the PCA analysis of the headspace IR spectra of wood samples can be lowered and simplified.

Principal component analysis was applied to quantitatively compute for the variation of the headspace IR spectra with the different wood samples. From the score plot (Fig. 5), clustering of wood samples by their taxonomical species was observed. However, only the wood species of $D$. philippinensis and $P$. indicus were discriminated and the other three wood species have overlapping groupings. The overlapping of the wood species G. arborea and V. parviflora can be explained by their common taxonomical family Verbanaceae, but the overlapping of $A$. auriculaeformis to the two was rather peculiar

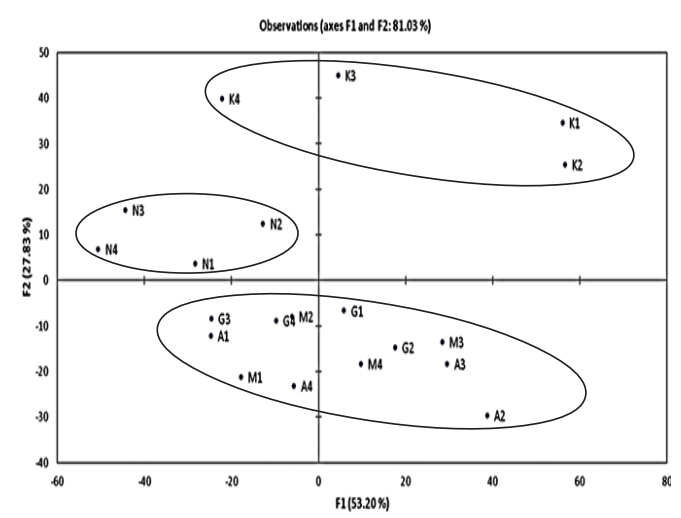

Figure 5. Score plot of the principal components of the absorbances in the wavenumber ranges 3550 $2900 \mathrm{~cm}^{-1}$ and $1700-600 \mathrm{~cm}^{-1}$ of each wood samples: P. indicus (N), G. arborea $(\mathrm{G}), V$. parviflora $(\mathrm{M})$, D. philippinensis $(\mathrm{K})$, and $A$. auriculaeformis (A) 


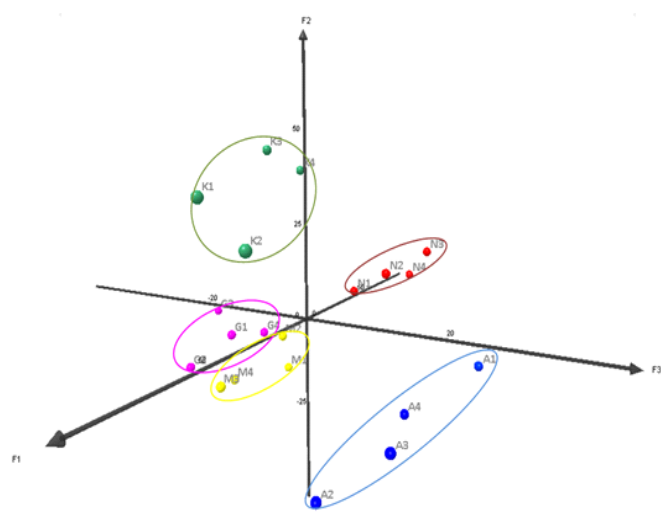

Figure 6. Three-dimensional scatter plot of the principal components of the absorbances in the wavenumber ranges $3550-2900 \mathrm{~cm}^{-1}$ and $1700-$ $600 \mathrm{~cm}^{-1}$ of each wood samples: P. indicus (N), G. arborea (G), V. parviflora (M), D. philippinensis (K), and A. auriculaeformis (A)

behavior because A. auriculaeformis is more related to $P$. indicus due to their common taxonomical family.

With the addition of another principal component (F3) to the PCA plot, the variability of the score plot increased from $81.03 \%$ to $89.57 \%$. The 3D PCA plot (Fig. 6) showed a more visible clustering of the wood species. The wood species Acacia has now been discriminated from the rest, while there was still a slight overlapping of the clusters of G. arborea and V. parviflora, both of which belonged to Verbanaceae family. The use of 3D PCA plot accomplished the objective of discriminating the five Philippine wood species using their headspace FTIR spectra.

Hierarchical cluster analysis (HCA) yielded the dendrogram shown in Fig. 7. The dendrogram showed the similarity relationships between each wood species where the horizontal axis is for the Euclidean distance among the groups and the vertical axis indicate the wood samples similarity. The dendrogram (Fig. 8) was successful in relating the samples with their species; $P$. indicus was shown to be rather

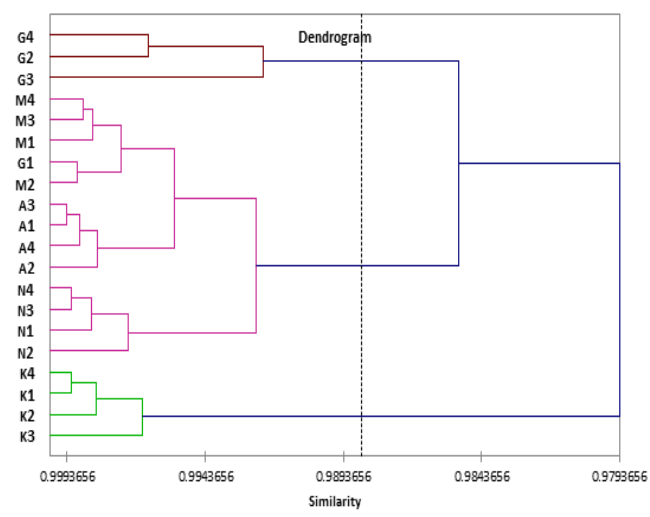

Figure 7. Dendrogram from HCA calculations of the sensor array responses to the wood samples: $P$. indicus $(\mathrm{N})$, G. arborea $(\mathrm{G})$, V. parviflora $(\mathrm{M})$, D. philippinensis $(\mathrm{K})$, and A. auriculaeformis (A)

related to Acacia, both belonging to the Fabaceae family. However, A. auriculaeformis was presented to be more related to V. parviflora and that G. arborea, both of which belonged to the Verbanaceae family. A G. arborea data point (G1) had been mixed in the group of V. parviflora species; this kind of occurrence is a typical dilemma of HCA in analyzing very large data set known as chaining [28]. The results of the HCA indicate that unfamiliar connections between the wood species can be revealed by the composition of the headspace of the wood samples.

\section{Conclusion}

The headspace fingerprinting of five Philippine wood species was achieved using vapor-phase FTIR spectroscopy technique. The headspace fingerprints of each wood species were interpreted by pattern recognition techniques. Unsupervised pattern recognition techniques depicted obvious clustering of wood species in the PCA plot and related groupings in the dendrogram from HCA, both of which provided clear discrimination of each wood species from each other. The results of PCA and HCA imply 
the efficiency of the headspace FTIR technique in discriminating the five Philippine wood species and its potential utility in the identification of wood species.

The use of headspace FTIR technique for wood headspace analysis offers simple and high throughput alternative towards other headspace analysis techniques, and has great potential for wood species identification. This technique can be utilized for fast screening analysis of wood samples but it needs to be accompanied by more accurate wood analysis techniques for critical inspections of contraband and endangered wood species.

\section{AcKNOWLedgment}

This work was funded through a thesis grant by the Department of Science and TechnologyScience Education Institute, Philippines. Wood samples were obtained through the kind assistance of the Facilities Management Office of the University of Santo Tomas. One of the authors (J.M. Kalaw) gratefully acknowledges DOST-SEI for scholarship.

\section{CONFlict OF INTEREST}

The authors declare that they have no conflict of interest.

\section{REFERENCES}

[1] Dormontt E, Boner M, Braun B, Breulmann G, \& Degen B. Forensic timber identification: It's time to integrate disciplines to combat illegal logging. Biological Conservation 2015; 191, 790-798.

[2] Koch G, Haag V, Heinz I, Richter H-G, \& Schmitt U. Control of Internationally Traded Timber - The Role of Macroscopic and Microscopic Wood Identification against Illegal Logging. Forensic Research 2015; 6, 317-321.

[3] Gasson P. How precise can wood identification be? Wood anatomy's role in support of the legal timber trade, especially CITES. IAWA Journal 2011; 32, 137-152.

[4] Wheeler EA \& Baas P. Wood identification - A review. IAWA Journal 1998; 19, 241-264.
[5] Wang S-Y, Wang Y-S, Tseng Y-H, Lin C-T, \& Liu C-P. Analysis of fragrance compositions of precious coniferous woods grown in Taiwan. Holzforschung 2006; 60, 528-532.

[6] Schreiner L, Loos HM, \& Buettner A. Identification of odorants in wood of Calocedrus decurrens (Torr.) Florin by aroma extract dilution analysis and two-dimensional gas chromatographymass spectrometry/ olfactometry. Analytical and Bioanalytical Chemistry 2017; 409(15), 37193729.

[7] Brattoli M, de Gennaro G, de Pinto V, Loiotile AD, Lovascio S, \& Penza M. Odour Detection Methods: Olfactometry and Chemical Sensors. Sensors 2011; 11, 5290-5322.

[8] Culleré L, Simón BFd, Cadahía E, Ferreira V, Hernández-Orte $P, \&$ Cacho J. Characterization by gas chromatography-olfactometry of the most odor-active compounds in extracts prepared from acacia, chestnut, cherry, ash and oak woods. LWT - Food Science and Technology 2013; 53, 240-248.

[9] Delgado de la Torre MP, Priego-Capote, F, \& Luque de Castro MD. Comparison of the volatile profile of vine-shoots and oak chips by headspacegas chromatography-mass spectrometry (HS-GC-MS). Analytical Methods. 2015; 7(5), 1758-1769.

[10] Liu Y, Shen J, \& Zhu XD. Headspace solid-phase microextraction for the determination of volatile organic compounds in Larix gmelini particles. Physics Procedia. 2012; 32, 605-613.

[11] Cordeiro JR, Martinez MIV, Li RWC, Cardoso AP, Nunes LC, Krug FJ, Paixao T, Nomura C, \& Gruber $J$. Identification of four wood species by an electronic nose and by LIBS. International Journal of Electrochemistry 2012; 2012, 1-5.

[12] Cordeiro JR, Li RWC, Takahashi ÉS, Rehder GP, Ceccantini G, \& Gruber J. Wood identification by a portable low-cost polymer-based electronic nose. RSC Advances 2016; 6(111), 109945 109949.

[13] Garneau FX, Riedl B, Hobbs S, Pichette A, \& Gagnon $\mathrm{H}$. The use of sensor array technology for rapid differentiation of the sapwood and heartwood of Eastern Canadian spruce, fir and pine. Holz als Roh- und Werkstoff 2004; 62, 470-473.

[14] Wilson AD, Lester DG, \& Oberle CS. Application of conductive polymer analysis for wood and woody plant identifications. Forest Ecology and Management 2005; 209, 207-224. 
[15] Wilson AD. Application of a conductive polymer electronic nose device to identify aged woody samples. In: Yurish S, Chilibon I, Carvalho V, \& Gervais-Ducouret $S$ (Eds) Proceedings of The 3rd International IARIA Conference on Sensor Device Technologies and Applications (Rome, Italy), pp. 77-82. (Wilmington, DE: Xpert Publishing Services, 2012).

[16] Dong D, Zheng W, Wang W, Zhao X, Jiao L, \& Zhao C. A new volatiles-based differentiation method of Chinese spirits using long path gasphase infrared spectroscopy. Food Chemistry 2014; 15, 45-49.

[17] Rana R, Müller G, Naumann A, \& Polle A. FTIR spectroscopy in combination with principal component analysis or cluster analysis as a tool to distinguish beech (Fagus sylvatica L.) trees grown at different sites. Holzforschung 2008; 62, 530-538.

[18] Wang S-N, Zhang F-D, Huang A-M, \& Zhou Q. Distinction of four Dalbergia species by FTIR, 2nd derivative IR, and 2D-IR spectroscopy of their ethanol-benzene extractives. Holzforschung 2017; 70, 503-510.

[19] Hobro AJ, Kuligowski J, Döll M, \& Lendl B. Differentiation of walnut wood species and steam treatment using ATR-FTIR and partial least squares discriminant analysis (PLS-DA). Analytical and Bioanalytical Chemistry 2010; 398, 2713-2722.

[20] Huang A, Zhou Q, Liu J, Fei B, \& Sun S. Distinction of three wood species by Fourier transform infrared spectroscopy and two dimensional correlation IR spectroscopy. Journal of Molecular Structure 2008; 883-884, 160-166.

[21] Rana R, Langenfeld-Heyser R, Finkeldey R, \& Polle A. FTIR spectroscopy, chemical and histochemical characterisation of wood and lignin of five tropical timber wood species of the family of Dipterocarpaceae. Wood Science and Technology 2010; 44, 225-242.
[22] Traoré M, Kaal J, \& Cortizas AM. Application of FTIR spectroscopy to the characterization of archeological wood. Spectrochimica Acta Part A: Molecular and Biomolecular Spectroscopy 2016; 153, 63-70.

[23] Dong D, Zheng W, Wang W, Zhao X, Jiao L, \& Zhao C. Analysis and discrimination of grape spoilage via volatiles: a comparison between long optical path Fourier-transform-infrared spectroscopy and sensor arrays. Analyst 2014; 139, 5028-5034.

[24] Dong D, Zhao C, Zheng W, Wang W, Zhao X, \& Jiao L. Analyzing strawberry spoilage via its volatile compounds using long path Fourier Transform Infrared Spectroscopy. Scientific Reports 2013; 3, 2585.

[25] Aganda KCC, Nonato MG, Sevilla III F, \& Santiago KS. Headspace Fourier transform infrared spectroscopy for the differentiation of Pandanus species. Talanta 2017; 164, 439-444.

[26] Department of Environment and Natural Resources. Department Administrative Order No. 78 (Series of 1987). (Philippines: Department of Environment and Natural Resources, 1987).

[27] International Union for Conservation of Nature and Natural Resources. The IUCN Red List of Threatened Species (Version 2017-3). 2015. http://www.iucnredlist.org (2018 March 2)

[28] Ecosystems Resarch and Development Bureau. Suitable species for Urban Forestry 3B. 2006; $18,6$.

[29] Ecosystems Resarch and Development Bureau. Yemane (Gmelina arborea Roxb) 2002; 14, 2-8.

[30] Silverstein RM, Webster FX, Kiemle DJ, \& Bryce $\mathrm{DL}$. Spectrometric identification of organic compounds (8 $8^{\text {th }}$ Edition). (New York, USA: John Wiley \& Sons Ltd., 2014). 